\title{
Inactivation of GPR30 reduces growth of triple-negative breast cancer cells: possible application in targeted therapy
}

\author{
Rainer Girgert • Günter Emons • Carsten Gründker
}

Received: 25 November 2011 / Accepted: 18 January 2012/Published online: 31 January 2012

(C) The Author(s) 2012. This article is published with open access at Springerlink.com

\begin{abstract}
Triple-negative breast cancers lack estrogen receptor $\alpha(\mathrm{ER} \alpha)$, progesterone receptor, and do not overexpress human epidermal growth factor receptor 2 (Her-2). They are neither susceptible to endocrine therapy nor to a therapy using the anti-Her-2 antibody, trastuzumab. Therefore, an efficient targeted therapy is warranted. Triple-negative breast tumors frequently express membrane bound estrogen receptor G-protein coupled receptor (GPR30). As proof of principle, we analyzed the consequences of a knock-down of GPR30 expression on the growth regulation of triple-negative breast cancer cell lines. Cells of triple-negative breast cancer cell lines were transfected with siRNA against GPR30 or control siRNA, and cell growth was stimulated either with $10^{-9} \mathrm{M}$ $17 \beta$-estradiol or $10^{-6} \mathrm{M}$ 4-hydroxytamoxifen. Cell proliferation was measured using Alamar blue staining. Activation of $\mathrm{c}$-Src and epidermal growth factor (EGF)receptor was assessed using western blot. Expression of $c$ fos was quantified by reverse transcription polymerase chain reaction. Seven days after transfection with siRNA, GPR30 mRNA in triple-negative breast cancer cell lines MDA-MB-435 and HCC1806 was reduced by 74 and $90 \%$, respectively. $10^{-8} \mathrm{M} 17 \beta$-estradiol enhanced proliferation of MDA-MB-435 to $129.6 \pm 5.4 \%$ of control $(p<0.05)$ and HCC1806 to $156.9 \pm 15.4 \%$ of control $(p<0.05)$, respectively. $10^{-6} \mathrm{M}$ 4-hydroxytamoxifen increased cell number of MDA-MB-435 to $121.0 \pm 6.9 \%$ of control $(p<0.05)$ and HCC1806 to $124.5 \pm 12.1 \%$ of control (n.s.), respectively. This increased proliferation by the two
\end{abstract}

R. Girgert $(\bowtie) \cdot$ G. Emons · C. Gründker Department of Obstetrics and Gynecology, Georg-August-University Göttingen, Robert-Koch-Strasse 40, 37075 Göttingen, Germany e-mail: rainer.girgert@med.uni-goettingen.de estrogenic compounds was completely prevented by knock-down of GPR30 expression in both cell lines. In control cells, activity of Src kinase was increased 3-fold by estradiol and 3.8-fold using 4-hydroxytamoxifen. Transactivation of the EGF-receptor was similarly increased in both cell lines by $17 \beta$-estradiol and 4-hydroxytamoxifen. Both compounds increased $c$-fos expression 1.5- and 3.1-fold, respectively. Knock-down of GPR30 expression completely abolished activation of all these signaling pathways responsible for enhanced proliferation. A pharmacological inhibition of GPR30 by specific small molecular inhibitors might prove to be an appropriate targeted therapy of triple-negative breast cancer in the future.

Keywords Triple-negative breast cancer - Targeted therapy $\cdot$ GPR30 $\cdot$ siRNA $\cdot$ Signal transduction
Abbreviations
EGF Epidermal growth factor
$\mathrm{ER} \alpha \quad$ Estrogen receptor $\alpha$
Erk Extracellular signal-regulated kinase
FCS Fetal calf serum
GPR30 G-protein coupled receptor
RT-PCR Reverse transcription polymerase chain reaction
PARP Poly-(ADP-ribose) polymerase

\section{Introduction}

Breast cancer is the most frequent malignancy in women. Endocrine therapy with the anti-estrogen tamoxifen or aromatase inhibitors achieves an overall survival of about $82 \%$ of patients after 8 years of treatment [1]. A subgroup of tumors expressing neither ER $\alpha$ nor progesterone 
receptor and not overexpressing Her-2 accounting for $15-20 \%$ of all breast tumors is called triple-negative breast cancer. These tumors, not susceptible to endocrine therapy, are currently treated with conventional chemotherapy. The death rate of patients with triple-negative breast cancer is double as high as in the case of ER $\alpha$-positive tumors [2].

Triple-negative breast cancers frequently carry mutations of the BRCA1 gene, for this reason, they turn out to be sensitive to platinum compounds. The combination of platinum and the epidermal growth factor (EGF)-R antibody Cetuximab increased the response rate from 30 to $49 \%$ [3]. Inhibitors of poly-ADP-ribose polymerase (PARP) were also found to be promising in triple-negative breast cancer $[4,5]$.

In MDA-MB-435 and MDA-MB-231 cells, lacking detectable expression of ER $\alpha$, Tsai et al. [6] observed a rapid phosphorylation of protein kinase Akt at $\mathrm{Ser}^{473}$ after stimulation with $17 \beta$-estradiol. Adenylate cyclase activity was increased in MCF-7 breast cancer cells by $17 \beta$-estradiol within minutes leading to an activation of protein kinase $\mathrm{A}$ [7]. An activation of the MAP-kinase extracellular signalregulated kinase (Erk) was also observed after short time stimulation of MCF-7 breast cancer cells with $17 \beta$-estradiol $[8,9]$. It was assumed that an estrogen receptor resides at the plasma membrane [10]. Finally, the G-protein coupled receptor, GPR30, was identified to be responsible for most of the non-genomic signaling events of $17 \beta$-estradiol $[11,12]$. Binding of $17 \beta$-estradiol to GPR30 leads to a dissociation of the heterotrimeric G-protein complex. The $\beta \gamma$-subunit activates the tyrosine kinase Src [13]. Subsequently, EGF from the extracellular matrix elicits the autophosphorylation of the EGF-receptor leading to the activation of the ras-MAPkinase pathway [14].

GPR30 has been proposed to be an excellent new therapeutic target for the treatment of triple-negative breast cancer [15].

In addition to $17 \beta$-estradiol, selective estrogen receptor modulator, tamoxifen, and complete ER $\alpha$ antagonist, fulvestrant, bind to GPR30 and induce adverse effects in breast cancer cells [11].

The experiments described in this report were performed to elucidate the role of GPR30 in the proliferative response of triple-negative breast cancer cells to $17 \beta$-estradiol and anti-estrogen 4-hydroxytamoxifen. For this purpose, GPR30 expression was reduced in two triple-negative breast cancer cell lines using specific siRNA. The consequences of the knock-down of GPR30 expression were analyzed at several points along the signaling pathway of GPR30 after stimulation with either $17 \beta$-estradiol or 4-hydroxytamoxifen. The enhancement of proliferation of the triple-negative cell lines by $17 \beta$-estradiol or 4-hydroxytamoxifen was completely prevented by the knockdown of GPR30.

\section{Materials and methods}

Reagents

17 $\beta$-Estradiol (E2), 4-hydroxytamoxifen, insulin, and transferrin were purchased from Sigma-Aldrich (Deisendorf, Germany). siRNA for GPR30 and non-specific control siRNA were obtained from SantaCruz Biotech (Santa Cruz, CA).

Cell lines

MDA-MB-435 [16] was purchased from ATCC (Manassas, $\mathrm{VA}$ ) and maintained in phenol red-free DMEM (Biochrom, Berlin, Germany) supplemented with $2 \mathrm{mM}$ glutamine, $6 \mathrm{ng} / \mathrm{ml}$ insulin, $10 \mathrm{ng} / \mathrm{ml}$ transferrin, penicillin $(50 \mathrm{U} / \mathrm{ml})$, streptomycin $(50 \mu \mathrm{g} / \mathrm{ml})$ from Gibco (Paisley, UK), and $5 \%$ fetal bovine serum (Biochrom, Berlin).

Breast cancer cell line HCC1806 was purchased from ATCC (Manassas, VA). Cells were maintained in phenol red-free MEM with Earle's salts supplemented with 5\% fetal calf serum (FCS, Biochrom, Berlin), $2 \mathrm{mM}$ glutamine, and $50 \mathrm{U} / \mathrm{ml}$ penicillin/streptomycin (Gibco, Paisley, UK).

\section{Transfection with siRNA}

$4 \times 10^{5}$ Cells of each triple-negative breast cancer cell line were seeded in $2 \mathrm{ml}$ growth medium into $25 \mathrm{~cm}^{2}$ culture flasks and grown to $80 \%$ confluence.

GPR30 siRNA (sc-60743) and nonspecific control siRNA (sc-37007) from SantaCruz (Santa Cruz, CA) were dissolved in RNAse-free water at a concentration of $10 \mu \mathrm{M}$. Sixteen microliters of each siRNA were diluted in $400 \mu \mathrm{l}$ transfection medium (sc-36868). In addition, $32 \mu \mathrm{l}$ transfection reagent (sc-29528) was added to another $400 \mu \mathrm{l}$ transfection medium. Equal volumes of the diluted siRNA and transfection reagent were mixed and incubated at room temperature for $45 \mathrm{~min}$.

Growth medium was removed from the culture flasks, and $2 \mathrm{ml}$ transfection medium (sc-36868) was added to the cells. After $10 \mathrm{~min}$ at $37^{\circ} \mathrm{C}$, transfection medium was replaced by the mixture of siRNA and transfection reagent, and the transfection was started. After $6 \mathrm{~h}, 2 \mathrm{ml}$ of a growth medium containing a twofold concentration of FCS and antibiotics was added to the transfected cells. After further $18 \mathrm{~h}$, the remaining siRNA was aspirated and cells were grown in normal culture medium until transfected cells were used for analysis.

\section{RT-PCRs}

RNA of the transfected breast cancer cells was purified using the RNeasy-kit (Qiagen, Hilden, Germany). 
$200 \mathrm{ng}$ of each RNA was transcribed using $400 \mathrm{U}$ Superscript reverse transcriptase (Invitrogen, Karlsruhe, Germany) in the presence of $0.5 \mu \mathrm{M}$ oligo-dT primer for $60 \mathrm{~min}$ at $37^{\circ} \mathrm{C}$. Five microliter of the resulting cDNA was amplified with $1 \mathrm{U}$ Taq polymerase (Peqlab, Erlangen, Germany) in the presence of $200 \mu \mathrm{M}$ dNTPs and $200 \mathrm{nM}$ of the appropriate primers.

\section{GPR30: primer A: AGTCGGATGTGAGGTTCAG Primer B: TCTGTGTGAGGAGTGCAAG c-fos: primer A: GAGATGGAGATCGGTATGGT Primer B: CAGGTCTGAATCAGTGCCTT}

Optimal PCR conditions for each gene were ascertained, guaranteeing that generation of the PCR products was in the exponential phase. Therefore, cDNA of GPR30 was amplified by 28 cycles and $c$-fos by 32 cycles. As reference, the RNA of the ribosomal protein L7 was amplified by 20 cycles.

PCR products were separated in a $2 \%$ agarose gel (Type IV, special high EEO, Sigma Chemicals, Steinheim, Germany) in $0.5 \times \mathrm{TBE}$ buffer at $100 \mathrm{~V}$ for $30 \mathrm{~min}$. Gels were stained in ethidium bromide $(2 \mu \mathrm{g} / \mathrm{ml})$ for $30 \mathrm{~min}$ and photographed on a transilluminator using a CDS camera (TD20, Kodak, Rochester).

\section{Proliferation assays}

The proliferation assays for $17 \beta$-estradiol and 4-hydroxytamoxifen were performed in phenol red-free medium supplemented with charcoal depleted serum (CD-FCS) as previously described [16]. CD-FCS was prepared according to the procedure described by Stanley et al. [17].

In brief, 2,000 cells/well were seeded in $100 \mu \mathrm{l} \mathrm{CD-FCS}$ medium (10\% CD-FCS) into 96-well plates. After attachment of the cells, $100 \mu \mathrm{l}$ CD-FCS medium containing either vehicle (control) or $17 \beta$-estradiol $\left(10^{-9}\right.$ and $\left.10^{-8} \mathrm{M}\right)$ or 4-hydroxytamoxifen $\left(10^{-7}\right.$ and $\left.10^{-6} \mathrm{M}\right)$ were added to four replicate wells for each concentration.

Cells were grown for 7 days at $37^{\circ} \mathrm{C}, 5 \% \mathrm{CO}_{2}$, and saturated humidity. Cell number was determined by a colorimetric method using Alamar blue (Biosource, Solingen, Germany) [16].

Proliferation assays were performed at least three times in quadruplicates with different passages. Means and standard deviations of the optical density (OD) of the replicates were calculated.

Assays of GPR30 signaling

For analysis of GPR30 signal transduction pathway, $10^{6}$ cells/well were plated in serum-free culture medium into 6 -well plates $(35 \mathrm{~mm})$. Cells were serum starved for $24 \mathrm{~h}$ to synchronize the $17 \beta$-estradiol-starved cells in $\mathrm{G}_{0}$-phase.
Serum starved cells were stimulated with $10^{-8} \mathrm{M}$ $17 \beta$-estradiol or $10^{-6} \mathrm{M}$ 4-hydroxytamoxifen for 10 or 20 min. Cells were harvested and cell pellets lysed in $100 \mu \mathrm{l}$ Cell lytic M (Sigma, Deisendorf, Germany), supplemented with protease inhibitor (Sigma, Deisendorf, Germany) and phosphatase inhibitor (Sigma, Deisendorf, Germany).

\section{Western blots}

Lysates of cells were cleared at $15,000 \mathrm{~g}$ for $5 \mathrm{~min}$, and the protein concentration in the supernatant was determined using the method of Bradford. $50 \mu \mathrm{g}$ of each sample was separated in a $7.5 \%$ polyacrylamide gel, blotted on PVDFmembrane, and sequentially detected with rabbit-antihuman primary antibodies: anti-phospho-Src (2113), antiSrc (2109), anti-phospho $\mathrm{Tyr}^{1173}$ EGF-receptor (324864) from Calbiochem (Darmstadt, Germany), anti-EGF-receptor antibody (2235) from Epitomics (Hamburg, Germany) and anti-actin from Sigma Chemicals (Deisendorf, Germany). After washing in TBST, blots were incubated with a 1:20.000 dilution of horseradish peroxidase-conjugated goat-anti-rabbit antibody (ECL, GE-Healthcare, Freiburg, Germany). After washing, blots were incubated with a chemoluminescence reagent and exposed to X-ray film (BiomaxMR, Kodak, Rochester, USA). Densitometric evaluations of the protein bands were normalized to actin.

\section{Densitometric evaluation of PCR products}

The bands of the PCR products were photographed using a CDS camera and evaluated by the Digital science 1D-software (Kodak, Rochester, USA). Values of the reverse transcription polymerase chain reaction (RT-PCR) products were normalized to the ribosomal protein L7.

Statistical analysis

The data were tested for significant differences by one-way analysis of variance followed by Student-Newman-Keuls' test for comparison of individual groups, after a Bartlett test had shown that variances were homogenous.

\section{Results}

Degradation of GPR30 mRNA by the treatment with siRNA

Triple-negative breast cancer cell lines MDA-MB-435 and HCC1806 were transfected with either non-specific siRNA (control; -si) or with siRNA specific for GPR30 (+si). Expression of mRNA for GPR30 was analyzed using RT-PCR at various time points after transfection in order to 
track the time course of the decline of GPR30 mRNA expression in both cell lines. Treatment with non-specific siRNA did not change expression of GPR30 mRNA (data not shown). In MDA-MB-435 cells transfected with GPR30 siRNA, the amount of GPR30 mRNA was gradually decreasing with growing time of exposure to siRNA. m-RNA for GPR30 was lowest 7 days after transfection with siRNA and started to increase again on day 10 of siRNA treatment (Fig. 1). Seven days after transfection of MDA-MB-435 cells, expression of GPR30 mRNA was reduced to $26 \%$.

In HCC1806 cells, expression of GPR30 mRNA decreased more slowly after transfection. Ten days after transfection, the amount of GPR30 mRNA was minimal and accounted for $10 \%$ of the expression in non-treated HCC1806 cells. L7 expression was unaffected by the treatment with GPR30 siRNA.

Inactivation of GPR30 slows down proliferation of triple-negative breast cancer cells

Proliferation of triple-negative breast cancer cell lines MDA-MB-435 and HCC1806 could be stimulated by $17 \beta$ estradiol and 4-hydroxytamoxifen (Fig. 2a, b). To test whether GPR30 is involved in the growth promoting effect of these two compounds, proliferation tests were performed with cells pretreated with siRNA against GPR30 $(+\mathrm{si})$. After treatment of MDA-MB-435 control cells ( - si) with $10^{-8} \mathrm{M} 17 \beta$-estradiol, the cell number increased to $129.6 \pm 5.4 \%$ of control $(\mathrm{C}=100 \% ; p<0.05)$. The $17 \beta$-estradiol-induced increase was completely obviated by knock-down of GPR30 ( $+\mathrm{si} ; p<0.05)$. After treatment of MDA-MB-435 control cells (-si) with $10^{-6} \mathrm{M}$ 4-hydroxytamoxifen, the cell number increased to $121.0 \pm 6.9 \%$ of control $(\mathrm{C}=100 \% ; p<0.05)$. Knockdown of GPR30 expression completely suppressed the effect of 4-hydroxytamoxifen on proliferation of MDAMB-435 cells (+si; 93\%; $p<0.05$ ) (Fig. 2a). In the

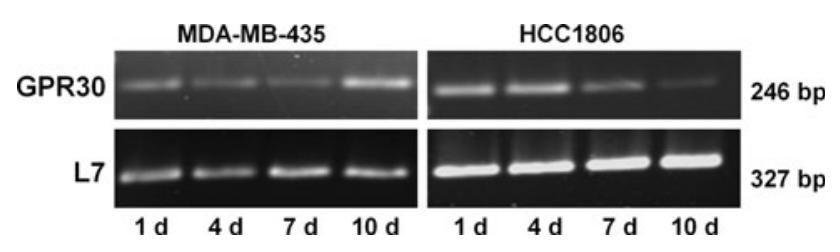

Fig. 1 Knock-down of GPR30 expression in triple-negative breast cancer cell lines. MDA-MB-435 and HCC1806 were transfected with siRNA specific for GPR30. mRNA of the cells was extracted 1, 4, 7, and 10 days after transfection, transcribed into cDNA and amplified by PCR using specific primers. L7, a ribosomal housekeeping gene, was amplified to prove the presence of equal amounts of RNA in each PCR reaction of the respective cell line. Representative results from three independent transfections
HCC1806 breast cancer cell line, treatment with $10^{-8} \mathrm{M}$ $17 \beta$-estradiol increased the number of control cells $(-\mathrm{si})$ to $156.9 \pm 15.4 \%$ of control $(\mathrm{C}=100 \% ; p<0.05)$. This growth stimulation was completely prevented by knockdown of GPR30 expression $(+\mathrm{si} ; 82 \% ; p<0.05)$. After treatment of $\mathrm{HCC} 1806$ control cells $(-\mathrm{si})$ with $10^{-6} \mathrm{M}$ 4-hydroxytamoxifen, the cell number increased to $124.5 \pm 12.1 \%$ of control $(\mathrm{C}=100 \%$; n.s. $)$. Knock-down of GPR30 expression completely suppressed the growth stimulation by 4-hydroxytamoxifen ( + si; $97 \%$; n.s.) (Fig. 2b).

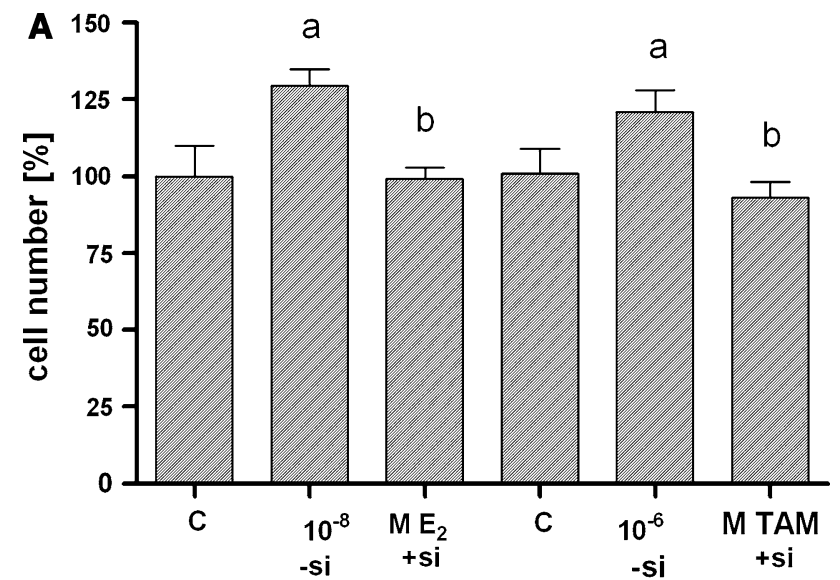

$\mathbf{B}$

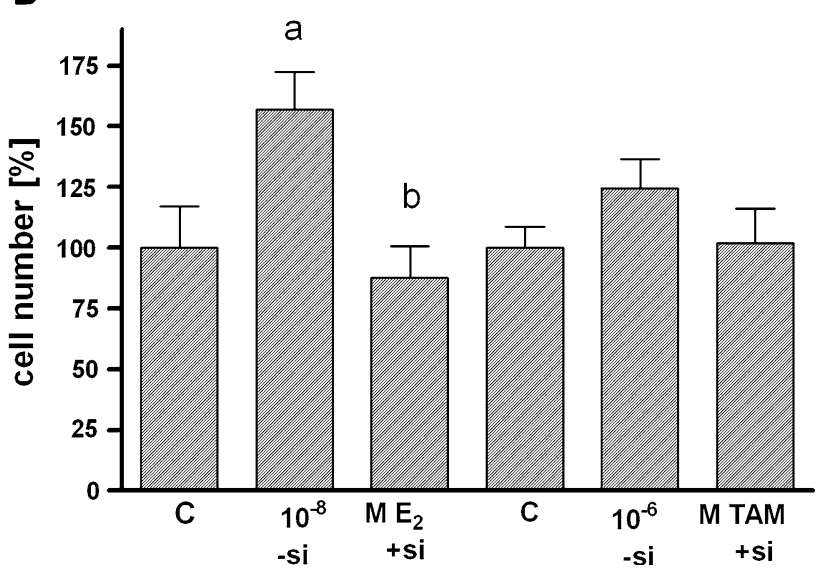

Fig. 2 Inhibition of proliferation of triple-negative breast cancer cells after knock-down of GPR30 expression. a MDA-MB-435, b HCC1806. Cells transfected with non-specific siRNA (-si) or with GPR30siRNA $(+$ si) were grown for 7 days in culture medium supplemented with $10 \%$ charcoal-treated FCS either in the absence or presence of $10^{-8} \mathrm{M} 17 \beta$ estradiol or $10^{-6} \mathrm{M}$ 4-hydroxytamoxifen. Cell number was evaluated in microwell plates by a colorimetric assay using Alamar blue. ODs measured in the non-stimulated wells (control) were set $100 \%$. The ODs estimated in the stimulated wells were divided by the values of the control well to give the relative cell number in $\%$ achieved under the indicated conditions. Doubling times of cell lines in hormone-depleted medium (control cells) were: MDA-MB-435: $\sim 48 \mathrm{~h}$; HCC1806: $\sim 36 \mathrm{~h}$. Data are mean values and SE of three independent experiments with four replicates. a $p<0.05$ versus control, b $p<0.05$ versus - si 
Impact of GPR30 knock-down on signal transduction of GPR30

Stimulation of GPR30 by $17 \beta$-estradiol is known to increase activity of the non-receptor tyrosine kinase Src. Treatment of MDA-MB-435 cells with $10^{-9} \mathrm{M}$ $17 \beta$-estradiol for 10 min clearly increased phosphorylation of Src at Tyr ${ }^{416}$ about threefold (Fig. 3, upper panel, lane 2). In MDA-MB-435 cells transfected for 7 days with GPR30 siRNA, the increase of Src phosphorylation by $17 \beta$-estradiol was completely abolished (lane 3 ). After treatment with $10^{-6}$ M 4-hydroxytamoxifen for $10 \mathrm{~min}$ phosphorylation of Src at $\mathrm{Tyr}^{416}$ increased by a factor of $3.8 \pm 0.6$. As seen for $17 \beta$-estradiol, inactivation of GPR30 by means of siRNA clearly obviated the activation of the kinase Src by 4-hydroxytamoxifen (Fig. 3, upper panel, lane 5).

Next step analyzed in the signal transduction of GPR30 was the transactivation of the EGF-R. In the course of GPR30 signaling, certain membrane bound matrix metalloproteases are activated and release EGF from the extracellular matrix. The degree of transactivation of the EGF-receptor was determined by detecting the amount of EGF-receptor phosphorylated at $\mathrm{Tyr}^{1173}$ on western blots. Phosphorylation of the EGF-receptor slightly increased after 10 min stimulation of MDA-MB-435 cells with $10^{-9}$ M 17 $\beta$-estradiol (Fig. 3, panel 3, lane 2). In cells transfected with siRNA against GPR30 (+si), the phosphorylation status of the EGF-receptor was much lower than in cells transfected with non-specific siRNA (-si; Fig. 3, panel 3, lane 3).

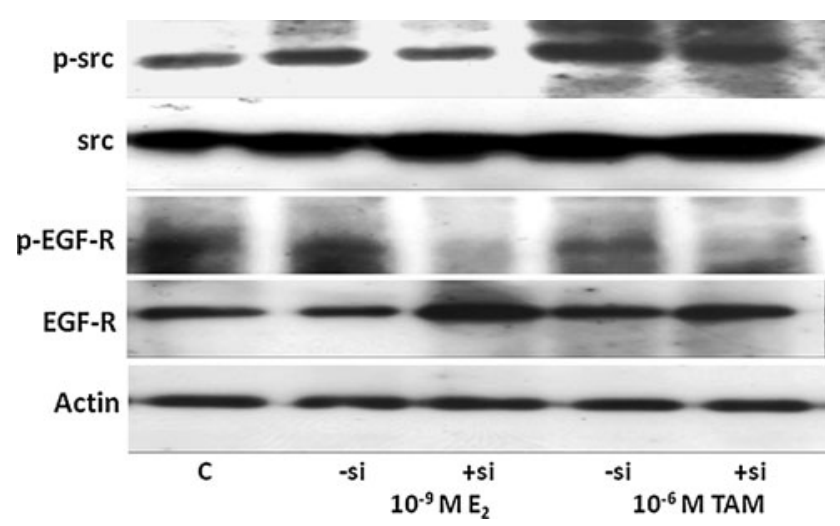

Fig. 3 Disruption of signal transduction of GPR30 in the siRNAtreated cells of the triple-negative breast cancer cell lines MDA-MB435. Cells transfected with siRNA $(+\mathrm{si})$ and control cells $(-\mathrm{si})$ were stimulated for $10 \mathrm{~min}$ with either $10^{-9} \mathrm{M} 17 \beta$-estradiol or $10^{-6} \mathrm{M}$ 4-hydroxytamoxifen. Cells were lysed, proteins separated in a polyacrylamide gel, blotted onto a PVDF-membrane, and the indicated proteins were sequentially detected with antibodies against phospho-src (panel 1), total-src (panel 2), phospho-EGF-receptor (panel 3), total EGF-receptor (panel 4), and actin, as housekeeping gene (panel 7). Representative results of three independent preparations
Treatment of the triple-negative breast cancer cells with $10^{-6} \mathrm{M}$ 4-hydroxytamoxifen stimulated the phosphorylation of the EGF-receptor more strongly than it was observed after treatment with $17 \beta$-estradiol (Fig. 3, panel 3, lane 4). Phosphorylation of EGF-receptor by 4-hydroxytamoxifen was almost completely abolished in cells transfected with siRNA directed against GPR30 (+si; Fig. 3, panel 3, lane 5).

The analysis of GPR30 signaling in the cell line HCC1806 showed similar consequences of the knockdown of GPR30 mRNA (data not shown).

Expression of $c$-fos protooncogene in response to $17 \beta$-estradiol and 4-hydroxytamoxifen

Expression of $c$-fos is a prerequisite of proliferation. Therefore, $c$-fos expression was analyzed in two triplenegative cell lines after treatment with either $17 \beta$-estradiol or 4-hydroxytamoxifen. Upregulation of $c$-fos expression by these two compounds in cells transfected with control siRNA (-si) was compared with $c$-fos expression of cells pretreated for 7 days with siRNA against GPR30 (+si).

In control cells of the cell line MDA-MB-435 (-si), expression of $c$-fos clearly increased after $30 \mathrm{~min}$ stimulation with $10^{-9} \mathrm{M} 17 \beta$-estradiol (1.5-fold) as well as $10^{-6}$ M 4-hydroxytamoxifen (3.1-fold, $p<0.001$ ) (Fig. 4a). Inactivation of GPR30 led to an almost complete inhibition of $c$-fos induction (Fig. 4a, lanes 5 and 6).

In HCC1806 cells, $17 \beta$-estradiol stimulated $c$-fos expression about 1.8 -fold $(p<0.01)$ and 4-hydroxytamoxifen led to an about twofold increase $(p<0.01)$ of $c$-fos expression (Fig. 4b). Suppression of GPR30 expression using siRNA blocked the induction of $c$-fos by both compounds in HCC1806 cells similar to the effects observed in MDA-MB-435 cells (Fig. 4b, lanes 5 and 6).

\section{Discussion}

The clinical outcome for patients with triple-negative breast cancer is still poor, despite intensive chemotherapy using cytotoxic drugs like platinum compounds. A search for more specific, targeted therapeutic options has been performed in recent years. In particular, PARP inhibitors were applied, taking advantage of a disturbed DNA-repair due to frequent BRCA1-mutations present in triple-negative breast cancer [4, 5]. Other investigators have chosen the frequently observed overexpression of the EGF-receptor as target using EGF-R antibody Cetuximab for a tailored therapy [3].

In the present study, we investigated the possible role of the GPR30, in the growth stimulation of triple-negative breast cancer cells. Immunohistochemical staining of 


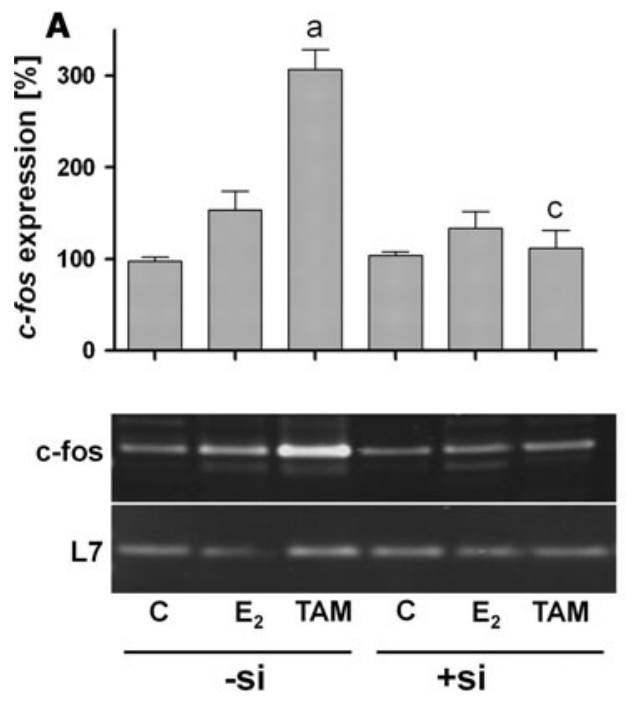

Fig. 4 Prevention of $c$-fos expression by the knock-down of GPR30. Triple-negative breast cancer cell lines, a MDA-MB-435 and b HCC1806, transfected with non-specific siRNA (control) or with GPR30siRNA were stimulated for $30 \mathrm{~min}$ either with $10^{-9} \mathrm{M}$ $17 \beta$-estradiol or $10^{-6} \mathrm{M} 4$-hydroxytamoxifen. mRNA was extracted, transcribed into cDNA, and amplified by PCR using primers specific

sections from triple-negative breast tumors revealed that almost all tumors were strongly positive for GPR30 (unpublished results). GPR30 was also found to be strongly expressed in the two triple-negative cell lines under investigation. Therefore, GPR30 expression is a feature frequently occurring in triple-negative breast cancer that might be used for targeted therapy.

Filardo et al. [11] intensively examined the role of GPR30 in response to $17 \beta$-estradiol and unraveled the signaling pathway downstream of this receptor. Ligands binding to GPR30 induce the dissociation of the heterotrimeric G-proteins. The $\beta \gamma$-subunit activates the tyrosine kinase Src. Subsequently, EGF-receptor is autophosphorylated at tyrosine ${ }^{1173}$ initiating the ras-MAP-kinase signaling, finally inducing proliferation of estrogen-stimulated cells independent of ER $\alpha[8,9]$. Most experiments elucidating the signaling pathways of GPR30 were performed with the breast cancer cell line SK-Br3 lacking expression of $\mathrm{ER} \alpha$ and $\mathrm{ER} \beta$. However, this SK-Br3 cell line does not represent a triple-negative breast cancer cell line, as SK$\mathrm{Br} 3$ cells overexpress Her2, whereas triple-negative breast cancer cells lack overexpression of human EGF-receptor 2 (Her-2) [18].

In contrast, many triple-negative breast tumors overexpress the EGF-receptor (Her-1) [19]. EGF is able to induce the expression of GPR30 [20]. 17 $\beta$-Estradiol activates the cytosolic kinase Src via GPR30 and Src activates matrix metalloproteases that release EGF from extracellular matrix. The subsequent induction of GPR30 expression leads to a positive feedback loop that boosts the induction
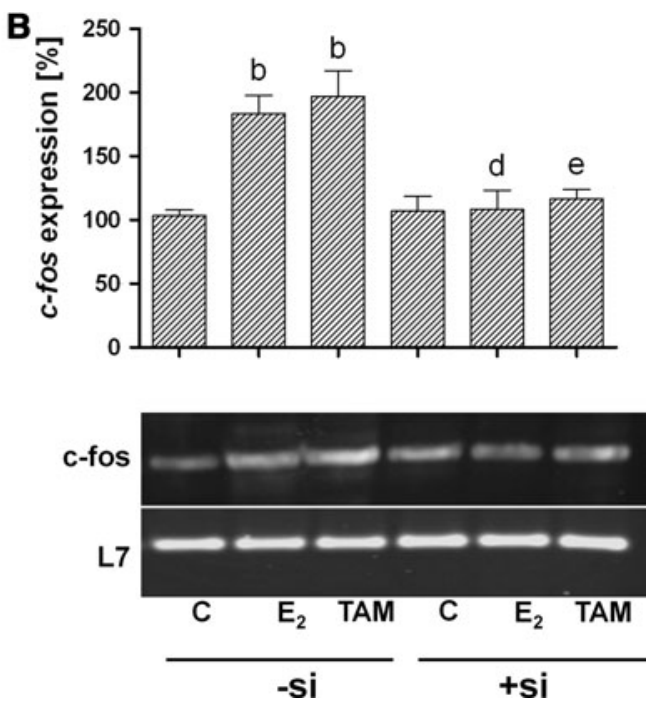

for $c$-fos. L7, a ribosomal housekeeping gene, was amplified to prove the presence of equal amounts of RNA in each PCR reaction of the respective cell line. Representative results of three separate experiments. (a) $p<0.001$ versus control, (b) $p<0.01$ versus control, (c) $p<0.001$ versus TAM, - si, (d) $p<0.01$ versus E2, - si, (e) $p<0.01$ versus TAM, - si

of proliferation by $17 \beta$-estradiol in triple-negative breast tumors.

In this report, we present evidence that in the triplenegative breast cancer cells studied, all necessary steps of the GPR30 signaling are activated in response to $17 \beta$-estradiol and 4-hydroxytamoxifen. Src phosphorylation is increased in both cell lines and EGF-receptor is phosphorylated at $\mathrm{Tyr}^{1173}$ after stimulation with both estrogenic compounds. Both kinases are more strongly activated by 4 -hydroxytamoxifen than by $17 \beta$-estradiol. The activation of these kinases was completely prevented in the triple-negative cell lines by knock-down of GPR30.

Some controversy exists about the nature of the estrogen receptor that is responsible for the rapid non-genomic effects of $17 \beta$-estradiol. Whereas some authors concluded that the activation of Src kinase, EGF-receptor, and the MAP-kinase Erk1/2 in breast cancer cells lacking ER $\alpha$ is elicited by GPR30 [11, 12], other authors predominantly hypothesize the presence of a truncated $\mathrm{ER} \alpha$ that localizes at the membrane supported by the scaffolding protein caveolin [10].

Opposite to this, the results of our experiments provide further evidence that the non-genomic effects of $17 \beta$-estradiol, like activation of $\mathrm{c}-\mathrm{Src}$, phosphorylation of the EGF-receptor, and increased expression of $c-f o s$, are dependent on the presence of GPR30. As we describe in this report, all these non-genomic effects of $17 \beta$-estradiol are detectable in the two triple-negative breast cancer cell lines and inactivation of GPR30 by means of siRNA prevent the activation of all pathways described above. 
Therefore, this report proves without doubt that GPR30 mediates the non-genomic effects of $17 \beta$-estradiol.

From the clinical point of view, the results presented in this report highlight GPR30 as an important new target for a more specific therapy of triple-negative breast cancer.

There have already been described some compounds that specifically inhibit GPR30. Estriol binds to GPR30 and inhibits GPR30 signaling weakly as shown for the upregulation of $c$-fos expression [21]. A substituted dihydroquinoline, G15, was identified that binds to GPR30 with an affinity of $20 \mathrm{nM}$. G15 was able to effectively block calcium mobilization by $17 \beta$-estradiol in the GPR30 expressing breast cancer cells SKBr3 [22]. Despite this, there is still a need to search for more effective inhibitors of GPR30 possessing a higher affinity and good bioavailability, before a therapy of triple-negative breast cancer targeting GPR30 may enter clinical trials.

Acknowledgments We thank Sonja Blume, Renate Dietrich, and Matthias Läsche for excellent technical assistance.

Conflict of Interest The authors declare that they have no conflict of interest.

Open Access This article is distributed under the terms of the Creative Commons Attribution License which permits any use, distribution, and reproduction in any medium, provided the original author(s) and the source are credited.

\section{References}

1. Dowsett M, Cuzick J, Ingle J, Coates A, Forbes J, Bliss J, Buyse M, Baum M, Buzdar A, Colleoni M, Coombes C, Snowdon C, Gnant M, Jakesz R, Kaufmann M, Boccardo F, Godwin J, Davies C, Peto R (2010) Meta-analysis of breast cancer outcomes in adjuvant trials of aromatase inhibitors versus tamoxifen. J Clin Oncol 28:509-518

2. Nofech-Mozes S, Trudeau M, Kahn HK, Dent R, Rawlinson E, Sun P, Narod SA, Hanna WM (2009) Patterns of recurrence in the basal and non-basal subtypes of triple-negative breast cancers. Breast Cancer Res Treat 118:131-137

3. Carey LA, Dees EC, Sawyer L, Gatti L, Moore DT, Collichio F, Ollila DW, Sartor CI, Graham ML, Perou CM (2007) The triple negative paradox: primary tumor chemosensitivity of breast cancer subtypes. Clin Cancer Res 13:2329-2334

4. Anders CK, Winer EP, Ford JM, Dent R, Silver DP, Sledge GW, Carey LA (2010) Poly(ADP-ribose) polymerase inhibition: "targeted" therapy for triple-negative breast cancer. Clin Cancer Res 16:4702-4710

5. Telli ML, Ford JM (2010) PARP inhibitors in breast cancer. Clin Adv Hematol Oncol 8:629-635

6. Tsai EM, Wang SC, Lee JN, Hung MC (2001) Akt activation by estrogen in estrogen receptor-negative breast cancer cells. Cancer Res 61:8390-8392

7. Aronica SM, Kraus WL, Katzenellenbogen BS (1994) Estrogen action via the cAMP signaling pathway: stimulation of adenylate cyclase and cAMP-regulated gene transcription. Proc Natl Acad Sci USA 91:8517-8521

8. Migliaccio A, Di Domenico M, Castoria G, de Falco A, Bontempo P, Nola E, Auricchio F (1996) Tyrosine kinase/p21ras/ MAP-kinase pathway activation by estradiol-receptor complex in MCF-7 cells. EMBO J 15:1292-1300

9. Visram H, Greer PA (2006) 17Beta-estradiol and tamoxifen stimulate rapid and transient ERK activation in MCF-7 cells via distinct signaling mechanisms. Cancer Biol Ther 5:1677-1682

10. Razandi M, Oh P, Pedram A, Schnitzer J, Levin ER (2002) ERs associate with and regulate the production of caveolin: implications for signaling and cellular actions. Mol Endocrinol 16: $100-115$

11. Filardo EJ, Quinn JA, Bland KI, Frackelton AR Jr (2000) Estrogen-induced activation of Erk-1 and Erk-2 requires the $G$ protein-coupled receptor homolog, GPR30, and occurs via transactivation of the epidermal growth factor receptor through release of HB-EGF. Mol Endocrinol 14:1649-1660

12. Revankar CM, Cimino DF, Sklar LA, Arterburn JB, Prossnitz ER (2005) A transmembrane intracellular estrogen receptor mediates rapid cell signaling. Science 307:1625-1630

13. Luttrell LM, Daaka Y, Lefkowitz RJ (1999) Regulation of tyrosine kinase cascades by G-protein-coupled receptors. Curr Opin Cell Biol 11:177-183

14. Maggiolini M, Vivacqua A, Fasanella G, Recchia AG, Sisci D, Pezzi V, Montanaro D, Musti AM, Picard D, Ando S (2004) The G protein-coupled receptor GPR30 mediates c-fos up-regulation by 17beta-estradiol and phytoestrogens in breast cancer cells. J Biol Chem 279:27008-27016

15. Chen JQ, Russo J (2009) ERalpha-negative and triple negative breast cancer: molecular features and potential therapeutic approaches. Biochim Biophys Acta 1796:162-175

16. Girgert R, Bartsch C, Hill SM, Kreienberg R, Hanf V (2003) Tracking the elusive antiestrogenic effect of melatonin: a new methodological approach. Neuroendocrinol Lett 24:440-444

17. Stanley ER, Palmer RE, Sohn U (1977) Development of methods for the quantitative in vitro analysis of androgen-dependent and autonomous Shionogi carcinoma 115 cells. Cell 10:35-44

18. Huang X, Gao L, Wang S, McManaman JL, Thor AD, Yang X, Esteva FJ, Liu B (2010) Heterotrimerization of the growth factor receptors erbB2, erbB3, and insulin-like growth factor-I receptor in breast cancer cells resistant to herceptin. Cancer Res 70:1204-1214

19. Nielsen TO, Hsu FD, Jensen K, Cheang M, Karaca G, Hu Z, Hernandez-Boussard T, Livasy C, Cowan D, Dressler L, Akslen LA, Ragaz J, Gown AM, Gilks CB, van de Rijn M, Perou CM (2004) Immunohistochemical and clinical characterization of the basal-like subtype of invasive breast carcinoma. Clin Cancer Res 10:5367-5374

20. Albanito L, Sisci D, Aquila S, Brunelli E, Vivacqua A, Madeo A, Lappano R, Pandey DP, Picard D, Mauro L, Ando S, Maggiolini M (2008) Epidermal growth factor induces G protein-coupled receptor 30 expression in estrogen receptor-negative breast cancer cells. Endocrinology 149:3799-3808

21. Lappano R, Rosano C, De Marco P, De Francesco EM, Pezzi V, Maggiolini M (2010) Estriol acts as a GPR30 antagonist in estrogen receptor-negative breast cancer cells. Mol Cell Endocrinol 320:162-170

22. Dennis MK, Burai R, Ramesh C, Petrie WK, Alcon SN, Nayak TK, Bologa CG, Leitao A, Brailoiu E, Deliu E, Dun NJ, Sklar LA, Hathaway HJ, Arterburn JB, Oprea TI, Prossnitz ER (2009) In vivo effects of a GPR30 antagonist. Nat Chem Biol 5:421-427 